\title{
Screening \& staging of colorectal cancer
}

\author{
Wolfgang Schima ${ }^{*}$, Anno Graser $^{2}$ \\ From International Cancer Imaging Society (ICIS) 14th Annual Teaching Course \\ Heidelberg, Germany. 9-11 October 2014
}

In Europe, colorectal cancer $(\mathrm{CRC})$ is the second most common cancer, and the second most common cause of death from cancer [1]. The vast majority of CRC develop from benign precursor lesions, so-called adenomatous polyps, which via the adenoma-carcinoma pathway may eventually transform into colon cancer. It has been shown that endoscopic removal of adenomas interrupts this pathway and subsequently reduces CRC incidence and cancer-related mortality. Thus endoscopic CRC screening programs have been instituted in many countries to reduced CRC cancer mortality. However, limited availability of colonoscopy and limited adherence of the population to colonoscopy-based screening programs is well documented. CT colonography (CTC) has evolved as an effective tool to detect small colorectal polyps, with a high sensitivity to diagnose adenomas $\geq 10 \mathrm{~mm}$ and advanced adenomas (with dysplasia) [2]. After negative screening CTC, clinically presenting CRC is rare in the 5 years following CTC [3].

Guidelines for staging of CRC have been developed by the European Society of Medical Oncology (ESMO) [4], which recommend MRI and/or endorectal ultrasound for local staging of rectal cancer (in order to decide which patients need neoadjuvant therapy). MRI is preferred in stenotic tumors or cancers in the upper third of the rectum. In patients with colon cancer, local staging (by CT) primarily seeks to exclude T4 disease with infiltration into other organs. Variability exists in different European countries regarding the use of contrast-enhanced MDCT of the abdomen and chest (to be preferred over chest X-ray) for evaluation of nodal disease and distant metastases. Assessment of lymph nodes based on size criteria alone has some limitations, because metastases can be found even in normal-sized lymph nodes [5,6]. FDG-PET is not recommended for staging [4]. It might be used for staging

\footnotetext{
* Correspondence: wolfgang.schima@khgh.at

'Department of Diagnostic and Interventional Radiology, Krankenhaus Goettlicher Heiland, KH der Barmherzigen Schwestern, and Sankt JosefKrankenhaus, Vinzenzgruppe, 1170 Vienna, Austria

Full list of author information is available at the end of the article
}

of patients with CT-detected synchronous liver metastases scheduled for liver surgery. However, a recent study showed that PET/CT in patients with potentially resectable liver metastases did not result in frequent change of management and did not improve overall survival [7]. CTC screening for CRC will be presented and CRC staging by MDCT and MRI will be highlighted.

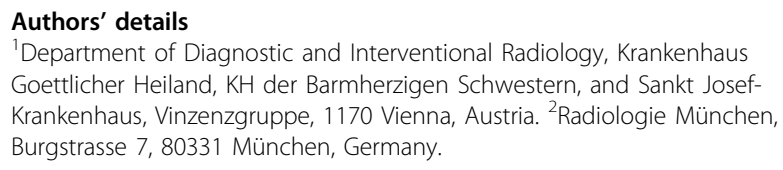

Published: 9 October 2014

\section{References}

1. Ferlay J, Autier P, Boniol M, Heanue M, Colombet M, Boyle P: Estimates of the cancer incidence and mortality in Europe in 2006. Ann Oncol 2007, 18:581-592.

2. De Haan MC, van Gelder RE, Graser A, Bipat S, Stoker J: Diagnostic value of CT-colonography as compared to colonoscopy in an asymptomatic screening population: a meta-analysis. Eur Radiol 2011, 21:1747-1763.

3. Kim DH, Pooler BD, Weiss JM, Pickhardt PJ: Five year colorectal cancer outcomes in a large negative CT colonography screening cohort. Eur Radiol 2012, 22:1488-1494.

4. Schmoll HJ, Van Cutsem E, Stein A, et al: ESMO Consensus Guidelines for management of patients with colon and rectal cancer. a personalized approach to clinical decision making. Ann Oncol 2012, 23:2479-2516.

5. Lahaye MJ, Beets $\mathrm{GL}$, Engelen $\mathrm{SM}$, et al: Locally advanced rectal cancer: MR imaging for restaging after neoadjuvant radiation therapy with concomitant chemotherapy. Part II. What are the criteria to predict involved lymph nodes? Radiology 2009, 252:81-91.

6. Beets-Tan RG, Lambregts DM, Maas M, et al: Magnetic resonance imaging for the clinical management of rectal cancer patients: recommendations from the 2012 European Society of Gastrointestinal and Abdominal Radiology (ESGAR) consensus meeting. Eur Radiol 2013, 23:2522-3125.

7. Moulton CA, Gu CS, Law CH, et al: Effect of PET before liver resection on surgical management for colorectal adenocarcinoma metastases: a randomized clinical trial. JAMA 2014, 311:1863-1869.

doi:10.1186/1470-7330-14-S1-08

Cite this article as: Schima and Graser: Screening \& staging of colorectal cancer. Cancer Imaging 2014 14(Suppl 1):O8. 